\title{
ANALYSING THE EFFECTS OF DIFFERENT LAND COVER TYPES ON LAND SURFACE TEMPERATURE USING SATELLITE DATA
}

\author{
A. Şekertekin ${ }^{\text {a }}{ }^{*}$, Ş. H. Kutoglu ${ }^{\text {a }}$, S. Kaya ${ }^{\text {b }}$, A. M. Marangoz ${ }^{\text {a }}$ \\ a BEU, Engineering Faculty, Geomatics Engineering Department 67100 Zonguldak, Turkey - (aliihsan_sekertekin, kutogluh, \\ aycanmarangoz)@ hotmail.com \\ b ITU, Civil Engineering Faculty, 80626 Maslak Istanbul, Turkey - (kayasina)@itu.edu.tr
}

SMPR 2015

KEY WORDS: Land Surface Temperature, Urbanization, Climate Change

\begin{abstract}
:
Monitoring Land Surface Temperature (LST) via remote sensing images is one of the most important contributions to climatology. LST is an important parameter governing the energy balance on the Earth and it also helps us to understand the behavior of urban heat islands. There are lots of algorithms to obtain LST by remote sensing techniques. The most commonly used algorithms are splitwindow algorithm, temperature/emissivity separation method, mono-window algorithm and single channel method. In this research, mono window algorithm was implemented to Landsat 5 TM image acquired on 28.08.2011. Besides, meteorological data such as humidity and temperature are used in the algorithm. Moreover, high resolution Geoeye-1 and Worldview-2 images acquired on 29.08.2011 and 12.07.2013 respectively were used to investigate the relationships between LST and land cover type. As a result of the analyses, area with vegetation cover has approximately $5{ }^{\circ} \mathrm{C}$ lower temperatures than the city center and arid land., LST values change about $10{ }^{\circ} \mathrm{C}$ in the city center because of different surface properties such as reinforced concrete construction, green zones and sandbank. The temperature around some places in thermal power plant region (ÇATES and ZETES) Çatalağz1, is about $5{ }^{\circ} \mathrm{C}$ higher than city center. Sandbank and agricultural areas have highest temperature due to the land cover structure.
\end{abstract}

\section{INTRODUCTION}

In recent years, climate change has been one of the most important problems that the ecological system of the world has been encountering. Global warming and climate change have been studied frequently by all disciplines all over the world and Geomatics Engineering also contributes to such studies by means of remote sensing, Global Navigation Satellite System (GNSS) etc.

Retrieving LST is crucial for climate change, especially for understanding urban heat islands and local climate changes (Voogt \& Oke, 2003; Kaya et al., 2012). The most commonly LST retrieval algorithms are split-window algorithm (Sobrino et al., 1996), temperature/emissivity separation method (Gillespie et al., 1998), mono-window algorithm (Qin et al., 2001) and single channel method (Jimenez-Munoz \& Sobrino, 2003). Generally three algorithms are used to obtain LST by using Landsat 5 TM data. These algorithms are radiative transfer equation method, single channel method and mono-window algorithm. Radiative transfer equation method is not applicable because during the satellite pass, atmospheric parameters must be measured in-situ. Single channel method and mono-window algorithm both present satisfying results. However, monowindow algorithm can be implemented simply and practically because of using simulated linear transformation equations for some parameters.

\section{STUDY AREA}

The study area, Zonguldak is located on the coast of Western Black Sea region of Turkey (Figure 1). The city is also one of the most forested cities in Turkey. However, with the exploitation of the coal reserves, progressive deforestation and massive loss of wetlands followed on. As a study area, Zonguldak has some characteristic areas close to each other such as industrial areas, sandbank and forested land.

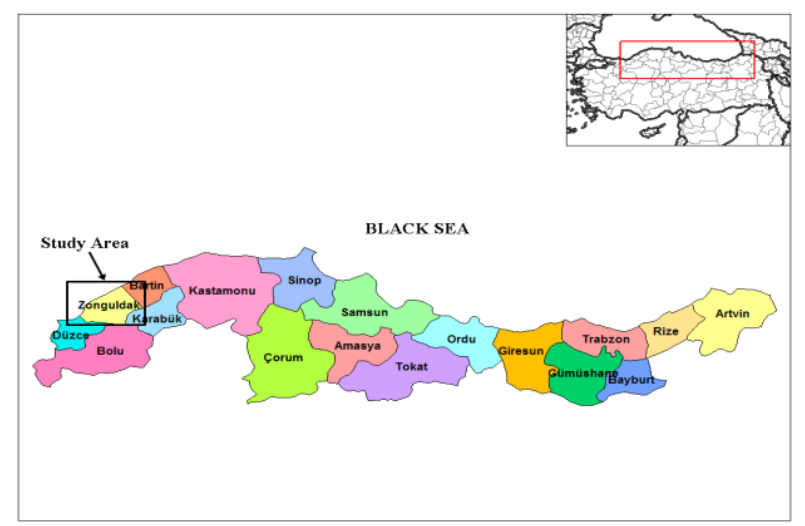

Figure 1. Study Area Zonguldak, Turkey

\section{MATERIAL AND METHOD}

In this research, Landsat 5 TM image acquired on 28.08.2011 was used to retrieve LST. High resolution satellite images, taken from Geoeye and Worlview-2, acquired on 29.08.2011 and 12.07.2013, respectively were used for regional analyses. Furthermore, meteorological data such as humidity and temperature were used in the algorithm.

\footnotetext{
${ }^{*}$ Corresponding author
} 
LST retrieval algorithms using remote sensing data are dependent on data specifications such as spectral features and number of thermal bands. Considering LST retrieval from Landsat 5 TM sensor data, it is usually preferred one of the algorithms, namely radiative transfer equation method, monowindow algorithm and single-channel algorithm.

Radiative transfer equation method reveals the best results, but it requires in-situ radiosonde measurement of the atmospheric parameters during the satellite passes. Mono-window algorithm is also an effective method which provides satisfying values of root mean square deviation (Sobrino et al., 2004). Therefore, mono-window algorithm can be preferred in the absence of radiosonde data, and so mono-window algorithm has been chosen in this research.

Mono-window algorithm, developed by Qin et al. (2001) for Landsat $6 \mathrm{TM}$ data, was used in this research. It is recommended for LST retrieval of the images with one thermal band. The method includes three main parameters, namely emissivity, atmospheric transmittance and effective mean atmospheric temperature (Qin et al., 2001). In order to apply mono-window algorithm, the required parameters are computed in a step-wise fashion which is elucidated below.

- Converting Digital Numbers (DNs) To Spectral Radiance Values

- Converting Spectral Radiance to Reflectance Values

- Converting Spectral Radiance to Brightness Temperature Values

- Estimation of Emissivity Values (Depends on Normalized Difference Vegetation Index (NDVI))

- Estimation of Atmospheric Transmittance (Depends on water vapour content)

- Calculation of Mean Atmospheric Temperature

- Calculation of LST

Firstly the images were prepared for processing. They were resampled and clipped as including the study area. Secondly radiometric corrections like converting digital numbers to spectral radiance values and converting spectral radiance to reflectance values were conducted. Then spectral radiance values of thermal bands were converted to brightness temperature by means of equation (1).

$$
\mathrm{T}=\frac{\mathrm{K}_{2}}{\ln \left(\frac{\mathrm{K}_{1}}{\mathrm{~L}_{\mathrm{\lambda}}}+1\right)}
$$

where $\quad \mathrm{T}=$ effective at-satellite temperature in Kelvin $\mathrm{L}_{\lambda}=$ spectral radiance at the sensor's aperture $\mathrm{K}_{1}, \mathrm{~K}_{2}=$ calibration constants

The other step is the estimation of Land Surface Emissivity (LSE) by using NDVI. A detailed estimation of LSE from NDVI was proposed by Zhang et al. (2006).

After that the estimation of mean atmospheric temperature $\left(\mathrm{T}_{\mathrm{a}}\right)$ via atmospheric temperature at ground $\left(\mathrm{T}_{0}\right)$ was proposed by Qin et al. (2001). Estimation of the last parameter, atmospheric transmittance $\left(\tau_{\mathrm{i}}\right)$, could be estimated from water vapor content $\left(\mathrm{w}_{\mathrm{i}}\right)$ as demonstrated in Table 1 (Qin et al., 2001).

\begin{tabular}{|c|c|c|c|c|}
\hline Profiles & $\begin{array}{c}\text { Water } \\
\text { Vapor } \\
\left(\mathbf{w}_{\mathbf{i}}\right)(\mathbf{g} / \mathbf{c} \\
\left.\mathbf{m}^{2}\right)\end{array}$ & $\begin{array}{c}\text { Transmittanc } \\
\text { e estimation } \\
\text { equation }\left(\boldsymbol{\tau}_{\mathbf{i}}\right)\end{array}$ & $\begin{array}{c}\text { Squared } \\
\text { correlation }\end{array}$ & $\begin{array}{c}\text { Standard } \\
\text { Error }\end{array}$ \\
\hline $\begin{array}{c}\text { High Air } \\
\text { Temperat } \\
\text { ure }\end{array}$ & $0.4-1.6$ & $\begin{array}{c}0.974290- \\
0.08007 \times w_{i}\end{array}$ & 0.99611 & 0.002368 \\
\cline { 2 - 5 } & $1.6-3.0$ & $\begin{array}{c}1.031412- \\
0.11536 \times w_{i}\end{array}$ & 0.99827 & 0.002539 \\
\hline $\begin{array}{c}\text { Low Air } \\
\text { Temperat } \\
\text { ure }\end{array}$ & $0.4-1.6$ & $\begin{array}{c}0.982007- \\
0.09611 \times w_{i}\end{array}$ & 0.99563 & 0.003340 \\
\cline { 2 - 5 } & $1.6-3.0$ & $\begin{array}{c}1.053710- \\
0.14142 \times w_{i}\end{array}$ & 0.99899 & 0.002375 \\
\hline
\end{tabular}

Table 1. Estimation of atmospheric transmittance from water vapour

Finally LST values could be obtained from equation (2), the equation of mono-window algorithm.

$$
\mathrm{T}_{\mathrm{s}}=\left\{\mathrm{a} \cdot(1-\mathrm{C}-\mathrm{D})+[\mathrm{b} \cdot(1-\mathrm{C}-\mathrm{D})+\mathrm{C}+\mathrm{D}] \cdot \mathrm{T}_{\mathrm{i}}-\mathrm{D} \cdot \mathrm{T}_{\mathrm{a}}\right\}=\mathrm{C}
$$

$$
\text { where } \quad \begin{aligned}
& \mathrm{a}=-67.355351 \\
& \mathrm{~b}=0.458606 \\
& \mathrm{C}=\varepsilon \mathrm{i} \times \tau \mathrm{i} \\
& \mathrm{D}=(1-\tau \mathrm{i})[1+(1-\varepsilon \mathrm{i}) \times \tau \mathrm{i} \\
& \mathrm{T}_{\mathrm{s}}=\mathrm{LST} \text { in Kelvin } \\
& \mathrm{T}_{\mathrm{i}}=\text { brightness temperature in Kelvin } \\
& \mathrm{T}_{\mathrm{a}}=\text { effective mean atmospheric temperature } \\
& \tau_{\mathrm{i}}=\text { atmospheric transmittance } \\
& \varepsilon_{\mathrm{i}}=\text { land surface emissivity } \\
& \mathrm{a}, \mathrm{b}=\text { algorithm constants }
\end{aligned}
$$

\section{RESULTS}

A model of the mono-window algorithm is illustrated in Figure 2. The whole process in this figure is programmed in Erdas Imagine Spatial Modeler for processing the data automatically. After obtaining LST, the image was classified using threshold method (Figure 3). Regional LST changes were analyzed using high resolution Geoeye and Worldview-2 images (Figure 4). Sample points over different land cover types were chosen and the results were presented in the graph below (Figure 5).

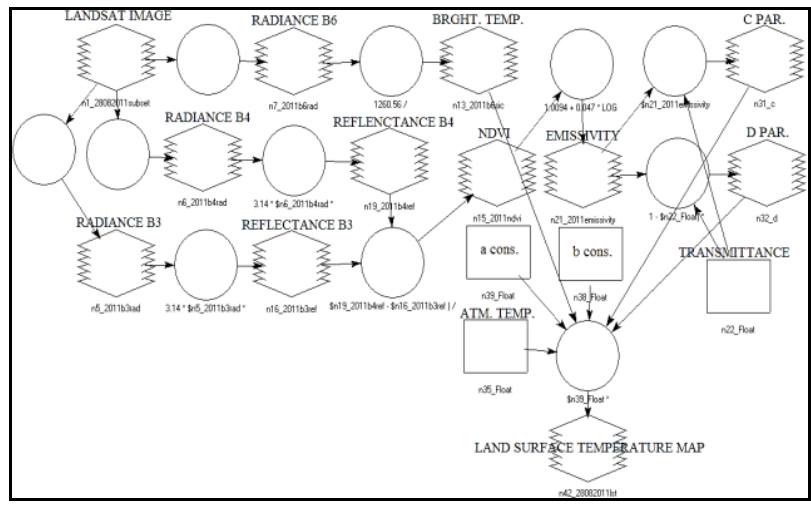

Figure 2. LST image model created in Erdas Imagine Spatial Modeler 


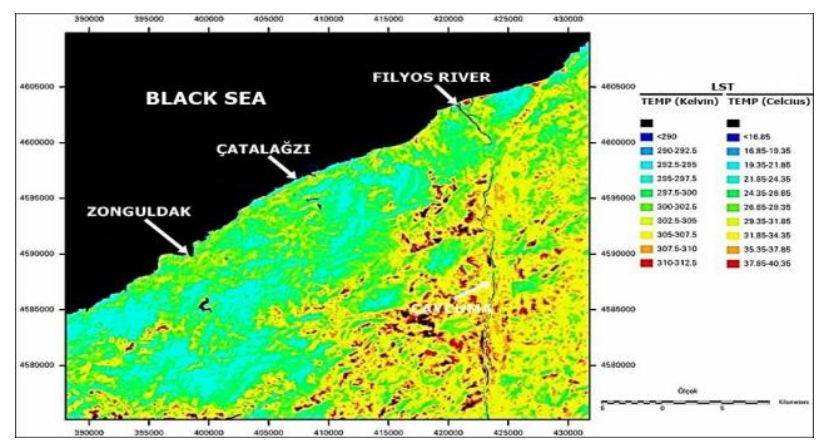

Figure 3. Classified LST image of study area

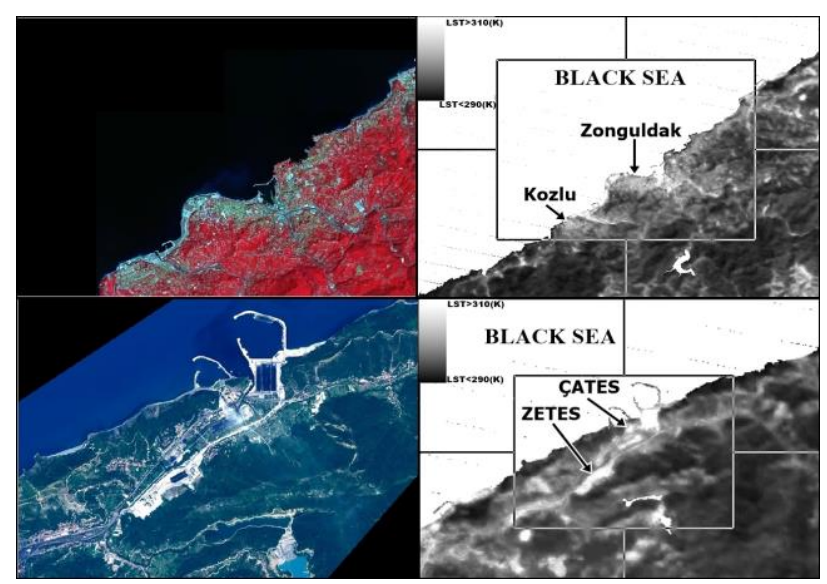

Figure 4. Association of high resolution images (left) and LST image (right)

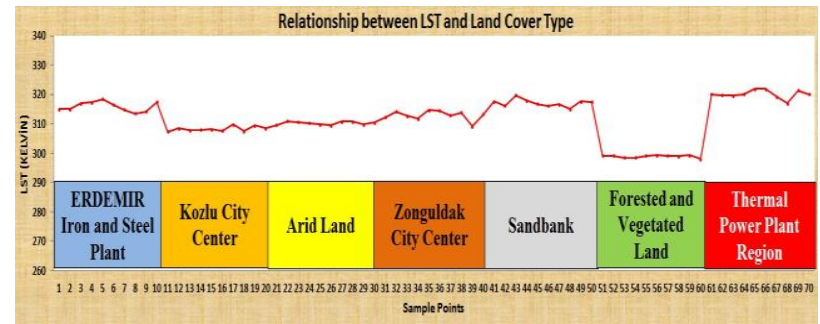

Figure 5. Relationship between LST and land cover types

Accuracy assessment of LST image was conducted using the linear correlation coefficient between the radiance and LST values. In general, the temperature values of LST image and local meteorological stations are compared for this evaluation. Because there is only one meteorological station in Zonguldak, the radiance and LST values were compared with each other for the accuracy assessment and the result was $86 \%$.

In this study, some characteristic areas like industrial regions, city centers, sandbank, arid land, vegetated and forest land were evaluated as different land cover types with regard to LST. As a result of the analyses, area with vegetation cover has approximately $5{ }^{\circ} \mathrm{C}$ lower temperatures than the city center and arid land., LST values change about $10{ }^{\circ} \mathrm{C}$ in the city center because of different surface properties such as reinforced concrete construction, green zones and sandbank. The temperature around some places in thermal power plant region Çatalağzı, is about $5^{\circ} \mathrm{C}$ higher than city center. Sandbank and agricultural areas have highest temperature due to the land cover structure. Furthermore, two plants ÇATES and ZETES also have high LST values compared the other land cover types.
Satellite imagery is an effective method to retrieve LST maps for large areas. Land cover types and the materials used as surface structure affect LST directly. Thus, it should be considered not to use materials in city centres that absorb the sun radiation too much for urban heat island effect. LST maps can be generated periodically by means of satellite images. Thus, it can not only be useful for agricultural activities but also for preparing a substructure especially for regional climate change researches.

\section{ACKNOWLEDGEMENTS}

Geoeye and Worldview-2 satellite images have been provided by BEUN Scientific Research Project: 2012-17-12-03.

\section{REFERENCES}

Gillespie, A. R., Rokugawa, S., Matsunaga, T., Cothern, J. S., Hook, S. J., \& Kahle, A. B. 1998. A temperature and emissivity separation algorithm for advanced space borne thermal emission and reflection radiometer (ASTER) images. IEEE Transactions on Geoscience and Remote Sensing, 36, 1113-1126. doi:10.1109/36.700995

Jimenez-Munoz, J. C., \& Sobrino, J. A. 2003. A generalized single-channel method for retrieving land surface temperature from remote sensing data. Journal of Geophysical Research, 108(D22), 4688. doi:10.1029/2003JD003480

Kaya, S., Basar, U. G., Karaca, M., \& Seker, D. Z. 2012. Assessment of Urban Heat Islands Using Remotely Sensed Data. Ekoloji, 21(84), 107-113. doi: 10.5053/ekoloji.2012.8412

Qin, Z., Karnieli, A., \& Berliner, P. 2001. A mono-window algorithm for retrieving land surface temperature from Landsat TM data and its application to the Israel-Egypt border region. International Journal of Remote Sensing, 22(18), 3719-3746. doi:10.1080/01431160010006971

Sobrino, J. A., Li, Z. L., Stoll, M. P., \& Becker, F. 1996. Multichannel and multi-angle algorithms for estimating sea and land surface temperature with ATSR data. International Journal of Remote Sensing, 17, 2089-2114. doi:10.1080/01431169608948760

Sobrinoa, J. A., Jimenez-Munoz, J. C., \& Paolini, L. 2004. Land surface temperature retrieval from LANDSAT TM 5. Remote Sensing of Environment, 90, 434-440. doi:10.1016/j.rse.2004.02.003

Voogt, J. A., \& Oke, T. R. 2003. Thermal remote sensing of urban climates. Remote Sensing of Environment, 86, 370-384. doi:10.1016/S0034-4257(03)00079-8

Zhang, J., Wang, Y., \& Li, Y. 2006. A C++ program for retrieving land surface temperature from the data of Landsat TM/ETM+ band6. Computers \& Geosciences, 32, 1796-1805. doi:10.1016/j.cageo.2006.05.001 